\title{
Radiological and clinical predictors of long-term outcome in rotator cuff calcific tendinitis
}

\author{
Pieter Bas de Witte ${ }^{1}$ Raymond A. van Adrichem ${ }^{1,2} \cdot$ Jasmijn W. Selten $^{1} \cdot$ \\ Jochem Nagels $^{1}$ • M. Reijnierse ${ }^{3}$ • Rob G. H. H. Nelissen ${ }^{1}$
}

Received: 10 September 2015 /Revised: 4 January 2016 / Accepted: 15 January 2016 / Published online: 5 March 2016

(C) The Author(s) 2016. This article is published with open access at Springerlink.com

\begin{abstract}
Objectives Knowledge on the epidemiology and long-term course of rotator cuff calcific tendinitis (RCCT) is scarce. We assessed demographics, radiological characteristics, and their association with long-term outcomes in a large patient group.

Methods Baseline demographics, radiological characteristics and treatment were recorded in 342 patients. Interobserver agreement of radiological measures was analyzed. Long-
\end{abstract}

Electronic supplementary material The online version of this article (doi:10.1007/s00330-016-4224-7) contains supplementary material, which is available to authorized users.

Pieter Bas de Witte

p.b.de_witte@lumc.nl

Raymond A. van Adrichem

R.A.van adrichem@lumc.nl

Jasmijn W. Selten

J.selten@lumc.nl

Jochem Nagels

J.Nagels@lumc.nl

M. Reijnierse

M.reijnierse@lumc.nl

Rob G. H. H. Nelissen

R.G.H.H.Nelissen@lumc.nl

1 Department of Orthopaedics, Leiden University Medical Center (LUMC), Postzone J11R, Postbus 9600,

2300 RC Leiden, The Netherlands

2 Department of Clinical Epidemiology, LUMC, Leiden, The Netherlands

3 Department of Radiology, LUMC, Leiden, The Netherlands term outcome was evaluated with questionnaires (WORC, DASH). The association of baseline characteristics with outcome was assessed.

Results Mean age was $49.0(\mathrm{SD}=10.0)$, and $59.5 \%$ were female. The dominant arm was affected in $66.0 \%$, and $21.3 \%$ had bilateral disease. Calcifications were on average $18.7 \mathrm{~mm}(\mathrm{SD}=10.1, \mathrm{ICC}=0.84(\mathrm{p}<0.001))$ and located $10.1 \mathrm{~mm}(\mathrm{SD}=11.8)$ medially to the acromion $(\mathrm{ICC}=0.77$ $(\mathrm{p}<0.001))$. Gärtner type I calcifications were found in $32.1 \%($ Kappa $=0.47(\mathrm{p}<0.001))$. After 14 years $(\mathrm{SD}=7.1)$ of follow-up, median WORC was 72.5 (range, 3.0-100.0; WORC $<60$ in $42 \%$ ) and median DASH 17.0 (range, 0.082.0). Female gender, dominant arm involvement, bilateral disease, longer duration of symptoms, and multiple calcifications were associated with inferior WORC. DASH results were similar.

Conclusions Many subjects have persisting shoulder complaints years after diagnosis, regardless of treatment. Female gender, dominant arm involvement, bilateral disease, longer duration of symptoms, and multiple calcifications were associated with inferior outcome. Radiological measures had moderate-to-good reliability and no prognostic value.

Key Points

- Most RCCT studies report on short-term outcome and/or small patients groups.

- In this large, long-term observational study, RCCT appeared to not be self-limiting in many subjects.

- Negative prognostic factors included female gender, more calcifications, dominant arm affected, and longer duration of symptoms.

- Interobserver agreement of general radiological RCCT measures is moderate to good.

- More rigorous diagnostics and treatment might be needed in specific RCCT cases. 
Keywords Rotator cuff · Calcific tendinitis · Treatment . Long-term $\cdot$ Epidemiology

\section{Introduction}

Rotator cuff calcific tendinitis (RCCT) is frequently diagnosed: reported incidence rates range from $6.8-54 \%$ [1-4]. Nevertheless, information on its epidemiology, radiological characteristics, long-term course and prognostic factors is scarce. In current literature, generally small populations are assessed, with short follow-up periods. This includes a recent trial from our institution, in which results of barbotage (needling and lavage) were superior to subacromial injections after one year of follow-up [5]. Surprisingly, results of both treatments appeared comparable in the case of Gärtner type I calcifications [6]. However, the measurement properties and reliability of most radiological RCCT characteristics, including the Gärtner classification, and their association with long-term outcome are unclear.

The current observational study is the first to assess longterm shoulder function in a large group of RCCT patients treated with barbotage (under local anesthesia) or more conservative methods. Additionally, patient demographics, radiological characteristics (size, location, Gärtner classification), interobserver agreement of radiological characteristics, and the association of these baseline parameters with long-term outcome are evaluated.

Typical RCCT symptoms are pain in the deltoid region, with variable functional impairment [7-9] and variable duration of symptoms, ranging from months to years [10-12]. Treatment of these generally self-limiting symptoms is usually conservative, e.g. with non-steroidal anti-inflammatory drugs (NSAIDs) and physical therapy. In the case of persisting or severe symptoms, more invasive treatments can be applied, including corticosteroids injections, barbotage, extracorporeal shock wave therapy (ESWT), or surgery [4, 7-9, 13-38]. Only a few studies have compared various treatments and their long-term effects. It is also unclear which patients follow a mild and self-limiting course, or who might benefit from more invasive treatment strategies. Consequently, clinical decision making is often based on personal experience and regional preferences.

With regard to the epidemiology of RCCT, several etiologies have been reported, including cell-mediated calcification, $\mathrm{RC}$ degeneration, $\mathrm{RC}$ overuse and micro-trauma, genetic predisposition, local metabolic or hemodynamic abnormalities, and subacromial impingement [4, 39-45]. Based on these theories, RCCT would predominantly affect the dominant arm or both arms in individuals with suboptimal vascular status (e.g. middle to older age, diabetes, or smokers) with frequent overhead activities. However, this has not been confirmed in clinical studies.
Radiological characteristics of RCCT, including the number, size, appearance (Gärtner classification) and location of calcifications, have been associated with clinical outcome by some $[3,23]$, but this association has been disputed by others [16, 23, 46-49]. There is also little knowledge of radiological calcification characteristics in large patient groups and their measurement properties, including reliability.

We assessed demographic and radiological characteristics in a large group of patients with RCCT. Long-term clinical outcomes were evaluated with questionnaires. Our objectives were to evaluate (1) baseline demographics and radiological characteristics, (2) interobserver agreement of common radiological RCCT measures, and (3) the association of demographic and radiological characteristics with long-term shoulder function. More knowledge on these factors may help in predicting patients' prognoses and in clinical decision making, i.e. when considering more invasive treatments methods for patients with persisting symptoms and negative prognostic factors.

\section{Materials and methods}

\section{Study population and baseline RCCT characteristics}

Since 1980, patients referred to the Leiden University Medical Center Orthopedics department received a medical diagnosis code. With these codes, all patients diagnosed with RCCT in the period of January 1980 until November 2009 were identified. During most of this period, our institution was considered a center of expertise with regard to RCCT and one of few regional institutions performing barbotage.

Medical records and radiology reports were reviewed for eligibility criteria by the first author, who was not involved in patient care. Patients were included if RCCT was demonstrated on available radiographs and/or noted in the radiology reports, and when aged $\geq 18$ years at time of diagnosis. Patients were excluded in the case that no medical records, radiographs or radiology reports were available, or if the diagnosis of RCCT was not mentioned in these records.

Accordingly, 420 had the RCCT diagnosis code. A total of 78 were excluded because no definite confirmation of RCCT could be made after reassessing all available medical and radiology records (radiographs and reports), or because they were $<18$ years old, leaving 342 confirmed RCCT patients available for the analysis of baseline demographics, radiographs, and disease characteristics (Fig. 1). Furthermore, these 342 patients were the source population for the follow-up evaluation.

The following baseline data were recorded: affected side(s), age, gender, date of diagnosis, age at diagnosis, type of treatment (barbotage, or conservative treatment (standard 


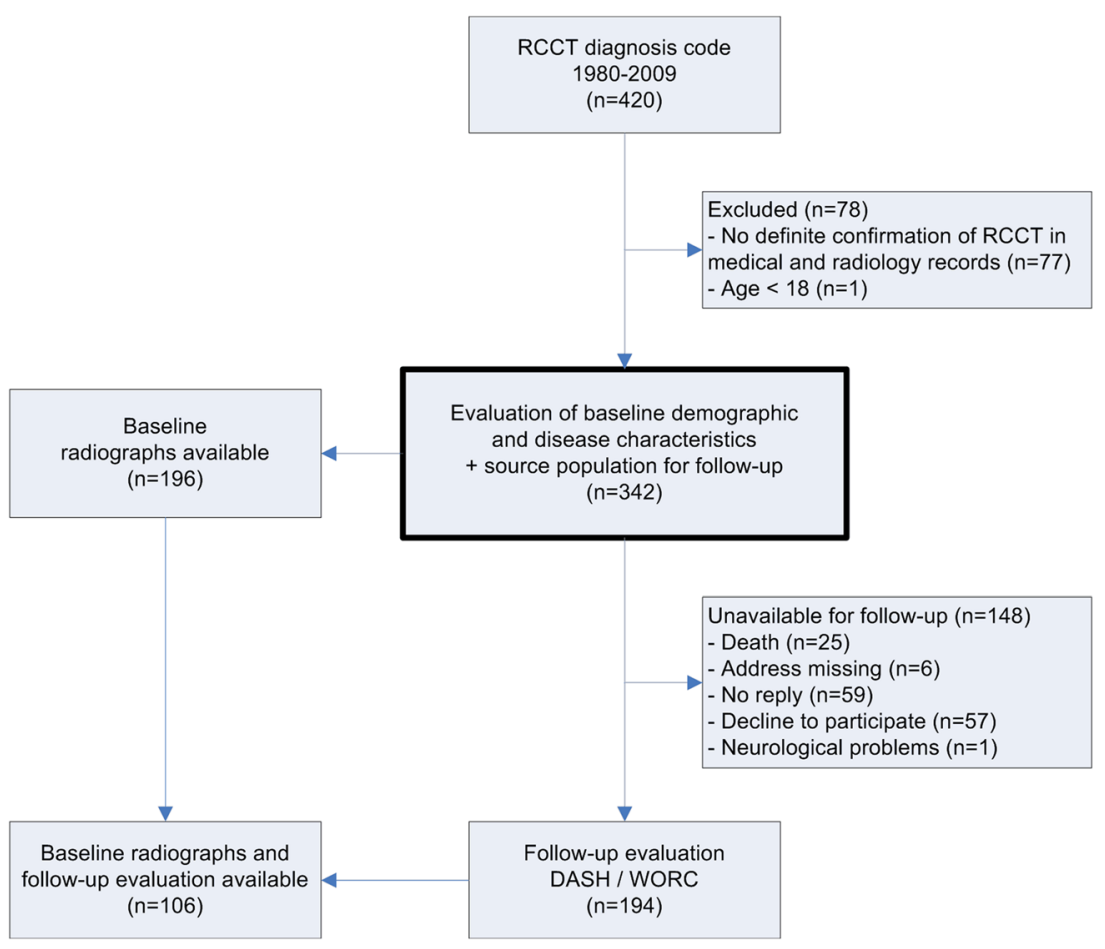

Fig. 1 Study flowchart

conservative treatment at the time included physical therapy, NSAIDs and/or subacromial corticosteroids injections)), duration of symptoms at presentation, diabetes, tendon problems at other sites, systemic inflammatory diseases, and other systemic or musculoskeletal diseases.

\section{Follow-up and questionnaires}

Addresses of the 342 patients and data on patient deaths were checked using the municipal personal records database. All available subjects were contacted by mail for completion of a general information form, the Western Ontario Rotator Cuff index (WORC), which was specifically developed to assess shoulder function and quality of life of patients with rotator cuff disorders, and the Disabilities of the Arm, Shoulder and Hand score (DASH) [50-52]. Also, arm dominance, any diseases for which medication was currently used, medical care history and any diseases affecting the shoulder and arm function were recorded. Subjects indicating the latter were excluded from further analyses. Reminders were sent after 4 and 8 weeks to all subjects from whom no reply was received.

Of the 342 confirmed RCCT patients, 31 could not be contacted due to unknown address or death. Of the remaining 311,252 replied (81.0\%), and 194 could be included for follow-up evaluation (Fig. 1). Demographic baseline data of the available (194 responders) and non-available subjects are depicted in Table 1.

As all subjects were contacted from November 2011 onwards, minimum follow-up was 2 years. All responders gave
Table 1 Baseline demographics and disease characteristics

\begin{tabular}{|c|c|c|c|c|c|c|}
\hline \multirow[b]{3}{*}{ Female gender } & \multirow{2}{*}{\multicolumn{2}{|c|}{$\begin{array}{l}\text { All subjects } \\
n=342\end{array}$}} & \multirow{2}{*}{\multicolumn{2}{|c|}{$\begin{array}{l}\text { Responders } \\
n=194\end{array}$}} & \multirow{2}{*}{\multicolumn{2}{|c|}{$\begin{array}{l}\begin{array}{l}\text { Non- } \\
\text { responders }\end{array} \\
n=148\end{array}$}} \\
\hline & & & & & & \\
\hline & 203 & $59.5 \%$ & 115 & $59.3 \%$ & 88 & $59.5 \%$ \\
\hline Age & 49.0 & [21-83] & 48.4 & [29-83] & 49.8 & {$[21-82]$} \\
\hline $\begin{array}{l}\text { Duration of symptoms } \\
\text { (median, months) }\end{array}$ & 23.5 & [0-196] & 18.0 & [0-192] & 24.0 & [0-196] \\
\hline Diabetic & 17 & $5.0 \%$ & 10 & $5.2 \%$ & 7 & $4.7 \%$ \\
\hline \multicolumn{7}{|l|}{ Affected side } \\
\hline Right & 161 & $47.1 \%$ & 88 & $45.4 \%$ & 73 & $49.3 \%$ \\
\hline Left & 99 & $28.9 \%$ & 49 & $25.3 \%$ & 50 & $33.8 \%$ \\
\hline Both & 73 & $21.3 \%$ & 49 & $25.3 \%$ & 24 & $16.2 \%$ \\
\hline Missing & 9 & $2.6 \%$ & 8 & $4.1 \%$ & 1 & $0.7 \%$ \\
\hline \multicolumn{7}{|l|}{ Arm dominance } \\
\hline Right & NA & NA & 165 & $85.9 \%$ & NA & NA \\
\hline Left & NA & NA & 21 & $10.9 \%$ & NA & NA \\
\hline Other & NA & NA & 6 & $3.1 \%$ & NA & NA \\
\hline Dominant side affected & NA & NA & 128 & $66.0 \%$ & NA & NA \\
\hline \multicolumn{7}{|l|}{ Treatment } \\
\hline Barbotage & 200 & $58.5 \%$ & 121 & $63.4 \%$ & 79 & $53.7 \%$ \\
\hline Conservative & 142 & $41.5 \%$ & 73 & $36.6 \%$ & 69 & $46.3 \%$ \\
\hline
\end{tabular}

Data displayed for all included subjects, and stratified for subjects returning follow-up questionnaires (responders) and non-responders

Barbotage: needling and lavage under local anesthesia; Conservative: e.g. NSAIDs, physical therapy, subacromial injections

[Range] 
written informed consent and the study was approved by the institutional Medical Ethics Committee (study ID: P09.239).

\section{Baseline radiological characteristics, interobserver agreement and association with long-term outcome}

Radiographs acquired within 1 year of the date of diagnosis and before eventual barbotage were used for the evaluation of baseline calcification characteristics. These were available for 204 shoulders in 196 patients. Due to national regulations, radiographs older than 15 years were generally destroyed.

Radiographs were evaluated independently by two trained researchers (PBW, RvA), blinded for the clinical status of patients. In a consensus meeting, final radiological outcome measures (see below) were determined for each subject. In the case of disagreement, radiographs were re-evaluated by an experienced musculoskeletal radiologist (MR), serving as an adjudicator.

Affected tendon(s), Size (mm), and number of calcifications per shoulder were recorded on anteroposterior (AP) (internal and external rotation) and axial views, which are all included in the standard shoulder protocol at our institution. Locations of all calcific deposits in each shoulder were further categorized using the system of Ogon et al., which we refer to as Location [3]. With this method, a line is drawn from the lateral border of the acromion, parallel to the glenoid, on external rotation AP radiographs. Location is the distance ( $\mathrm{mm}$ ) between this line and the medial border of the calcification (Fig. 2). More subacromial extension (negative Location value) has been reported a negative prognostic factor [3].

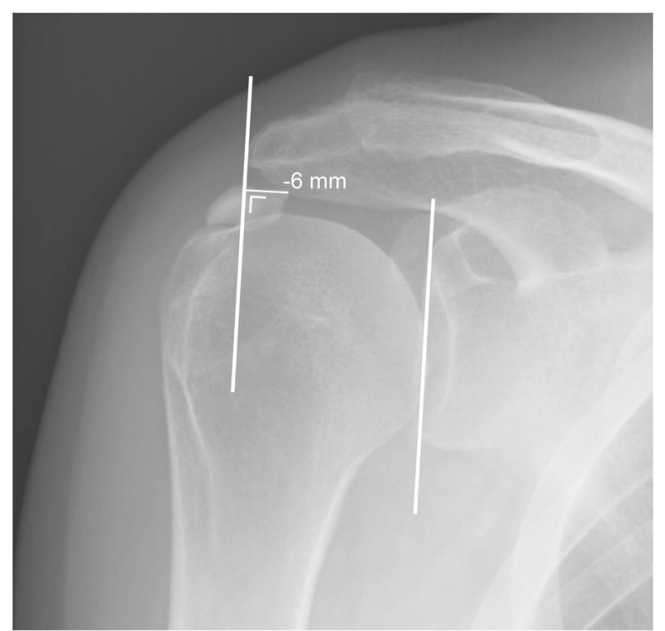

Fig. 2 Locations of the calcific deposits were evaluated using the system of Ogon et al., which we refer to as Location in this paper [3]. A line perpendicular to the most lateral border of the acromion is drawn, parallel to the glenoid, on external rotation AP radiographs. Location is the distance $(\mathrm{mm})$ between this line and the medial border of the calcification, where negative values represent a medial calcification border, i.e. between the glenoid and the drawn line
Calcific deposits were also assessed using Gärtners classification: Type I calcifications have a sharp border and a dense structure; Type II calcifications either have a sharp border and inhomogeneous structure or a vague border and a homogenous structure; Type III calcifications have a vague border, and are more or less transparent, with a cloudy appearance (Fig. 3) [6]. These types allegedly display the natural course of RCCT and are potentially valuable in determining patients' prognosis [23]. And in a recent trial at our institution, the results of barbotage were superior to subacromial injections in patients with Type II and III calcifications, but not in case of Type I calcifications [5].

For assessing interobserver agreement, metric measures (Size and Location) and Gärtner classifications of all available radiographs (analogue and digital) and all calcifications were used ( $\mathrm{n}=248$ calcifications in 196 patients). To evaluate the association of baseline radiological characteristics with longterm outcome, characteristics of the largest calcification per patient were used. For these final analyses, all radiographs could be used with regard to e.g. Gärtner classification and affected tendon, but for metric measures, only available digital radiographs $(\mathrm{n}=50)$ could be used, as their magnification factor was known and consistent.

\section{Statistical analysis}

Demographics and disease characteristics were expressed using proportions, means and standard deviations, or medians and ranges where appropriate. Data distributions were evaluated using histograms. Questionnaire data were processed similarly. In the case of a missing WORC item, its value was estimated by the mean of the other items in its domain, according to instructions of the designers of the WORC. In case of more missing values in a single domain, the questionnaire was excluded $(n=14)$. Similarly, 26 incomplete DASH questionnaires were excluded.

For calcification characteristics, interobserver agreement was assessed with the Kappa statistic for Gärtner classifications, and with paired t-tests and intraclass correlation coefficients (ICC) for Size and Location.

In this observational study, the association of baseline characteristics with long-term shoulder function was assessed with the WORC as a primary outcome. Using logistic regression (because of skewed outcomes for DASH and WORC scores), the univariate association of each recorded variable with inferior outcome was evaluated and expressed in odds ratios (OR) with $95 \%$ confidence intervals ( $95 \%$-CI). WORC-scores $\geq 80$ were defined as a good outcome. Similarly, DASH-scores $\leq 20$ were regarded as a good outcome. Sensitivity analyses were performed for alternative WORC and DASH cut-offs.

To gain more insight in independent prognostic factors, multivariable logistic regression models were constructed for the WORC and DASH. In order to avoid overfitting, no more than 

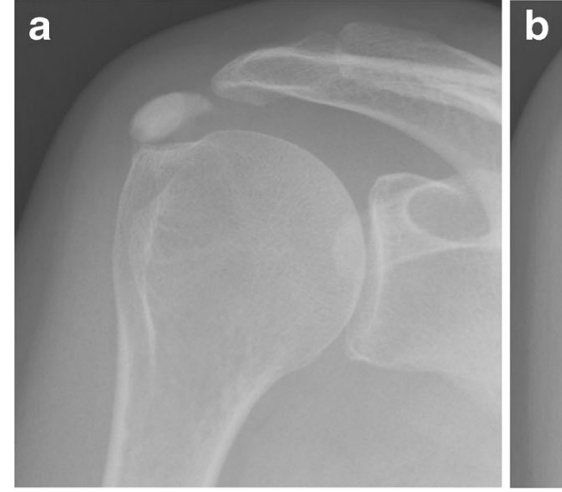

Fig. 3 Examples of Gärtner calcification classification types [6]. A) Gärtner type I: sharp border and a dense structure; B) Gärtner type II: either a sharp border and an inhomogeneous structure or a vague border and a homogenous structure; C) Gärtner type III: a vague border, more or less transparent in structure and a cloudy appearance

$\mathrm{p}=0.71)$ and for Location, $0.08 \mathrm{~mm}(95 \%-\mathrm{CI}:-1.16-1.00$; $\mathrm{p}=0.89)$, with ICCs of $0.84(\mathrm{p}<0.001)$ and $0.77(\mathrm{p}<0.001)$, respectively. The Kappa-value for the Gärtner classification was moderate, with a value of $0.466(\mathrm{p}<0.001)$. The Kappavalue was $0.471(\mathrm{p}<0.001)$ when assessing interobserver agreement for Gärtner classification I vs. II and III combined.

\section{Long-term shoulder function}

The 194 subjects who returned questionnaires had a mean follow-up of 14 years ( $\mathrm{SD}=7.1$, range 2-33, median 13 years). Mean current age was 62 years $(\mathrm{SD}=9.2$, range 39-89). Median WORC was 72.5 (range, 3.0-100.0) and median DASH 17.0 (range, 0.0-82.0).

For the WORC, $99(55 \%)$ of 180 available subjects had a WORC $<80$, and $76(42.2 \%)$ a WORC even below 60 (Fig. 4A). Univariate analyses demonstrated that patients with a longer duration of symptoms at presentation, bilateral disease, and dominant arm involvement had statistically significant lower long-term outcomes (WORC < 80) (Table 3). Additionally, with $\mathrm{OR}=1.82$ (95 \%-CI: 0.99-3.35, $\mathrm{p}=0.05$ ), female gender had a clinically relevant negative association with long-term outcome.

In total, 106 subjects had both baseline radiographs and clinical scores available. Results of univariate logistic regression analyses with radiological parameters are depicted in Tables 3 and 4. The number of calcifications (per shoulder) had an $\mathrm{OR}=2.1$ (95\%-CI: 0.97-4.62) for WORC $<80$, indicating that a larger number of calcifications was associated with inferior long-term shoulder function in our data.

The final multivariate WORC model included gender, age at follow-up, years after diagnosis, bilateral disease, dominant side involvement, and treatment method. Female gender had a significant negative effect: $\mathrm{OR}=2.2(95 \%$-CI: $1.1-4.2)$. Effect sizes for bilateral disease $(\mathrm{OR}=2.2(95 \%$-CI: 0.94 5.1)) and dominant arm involvement $(\mathrm{OR}=1.7$ (95 \%-CI:

observers for Size was $0.11 \mathrm{~mm}$ (95\%-CI: -0.46-0.67; 
Table 2 Baseline data obtained from available analog $(n=154)$ and digital radiographs $(\mathrm{n}=50)$

\begin{tabular}{|c|c|c|c|c|c|c|}
\hline & \multicolumn{2}{|c|}{ All subjects } & \multicolumn{2}{|c|}{ Responders } & \multicolumn{2}{|c|}{ Non-responders } \\
\hline & \multicolumn{2}{|c|}{$n=196$} & \multicolumn{2}{|c|}{$n=106$} & \multicolumn{2}{|c|}{$n=90$} \\
\hline \multicolumn{7}{|l|}{ Affected tendon(s) } \\
\hline Supraspinatus & 167 & $85.2 \%$ & 92 & $86.8 \%$ & 75 & $83.3 \%$ \\
\hline Infraspinatus & 33 & $16.8 \%$ & 19 & $17.9 \%$ & 14 & $15.6 \%$ \\
\hline Subscapularis & 34 & $17.3 \%$ & 21 & $19.8 \%$ & 12 & $13.3 \%$ \\
\hline \multicolumn{7}{|l|}{ Gärtner } \\
\hline 1 & 63 & $32.1 \%$ & 34 & $32.1 \%$ & 29 & $32.2 \%$ \\
\hline 2 & 111 & $56.6 \%$ & 65 & $61.3 \%$ & 46 & $51.1 \%$ \\
\hline 3 & 69 & $35.2 \%$ & 38 & $35.8 \%$ & 31 & $34.4 \%$ \\
\hline Size (mm) & 18.7 & [10.1] & 18.7 & {$[9.8]$} & 18.6 & {$[10.8]$} \\
\hline Location (mm) & -10.1 & {$[11.8]$} & -10.7 & {$[11.6]$} & -9.1 & {$[12.6]$} \\
\hline
\end{tabular}

There were 248 calcifications in 204 shoulders in 196 patients (multiple calcifications in 33 shoulders) with radiographs available

Percentages are reported with respect to the concerning number of patients and can be $>100 \%$ because of multiple calcifications in some patients

[SD]

0.79-3.6)) also indicated relevant negative effects, but did not reach statistical significance. There was no significant association for WORC outcome with applied treatment, either barbotage or more conservative methods (Table 3 ). Sensitivity analyses using WORC cut-off points $<70$ and $<90$ gave similar results (data not shown).

For the DASH, 75 (44.6\%) subjects scored $\geq 20$ points and $37(22.0 \%)$ subjects scored $\geq 40$ points, indicating inferior long-term shoulder function (Fig. 4B). There were no variables with significant effects found with univariate analyses (Table 4). The final multivariable model for the DASH included gender, age at questionnaire, years after diagnosis, bilateral disease, dominant side involvement, and treatment method. Also in this model, female gender had a statistically significant (negative) effect: $\mathrm{OR}=2.0$ (95\%-CI: 1.0-4.0) (Table 4). Sensitivity analyses using DASH cut-off points $>10$ and $>30$ gave similar results (data not shown).

\section{Discussion}

In this first study involving both a long-term follow-up and a large group of RCCT patients, the results show that many subjects have persisting shoulder complaints more than a decade after diagnosis, regardless of applied treatment modality (barbotage vs. conservative). With a mean follow-up of 14 years, about $55 \%$ had WORC scores below 80 points and $42.2 \%$ were even below 60 points, indicating severely impaired shoulder function. Dominant arm involvement, bilateral disease, longer duration of symptoms at presentation, larger number of calcifications and female gender all appeared to be negative prognostic factors for long-term shoulder function. We found no association of outcome with common radiological parameters (calcification size, location, Gärtner classification), and interobserver agreement was good for size and location, but only moderate for the Gärtner classification.

\section{Long-term follow-up}

Previous studies on calcific tendinitis have mostly reported on small populations with a relatively short follow-up. There are some studies with $>2$ years follow-up [10, 13, 53-61], or large patient groups $(n>100)[15,22,34,62-66]$, but the combination of both is scarce $[3,9,11]$. In one of the few larger RCCT cohorts with a long-term follow-up, Serafini et al. report good outcomes for both barbotage and conservative treatment, in
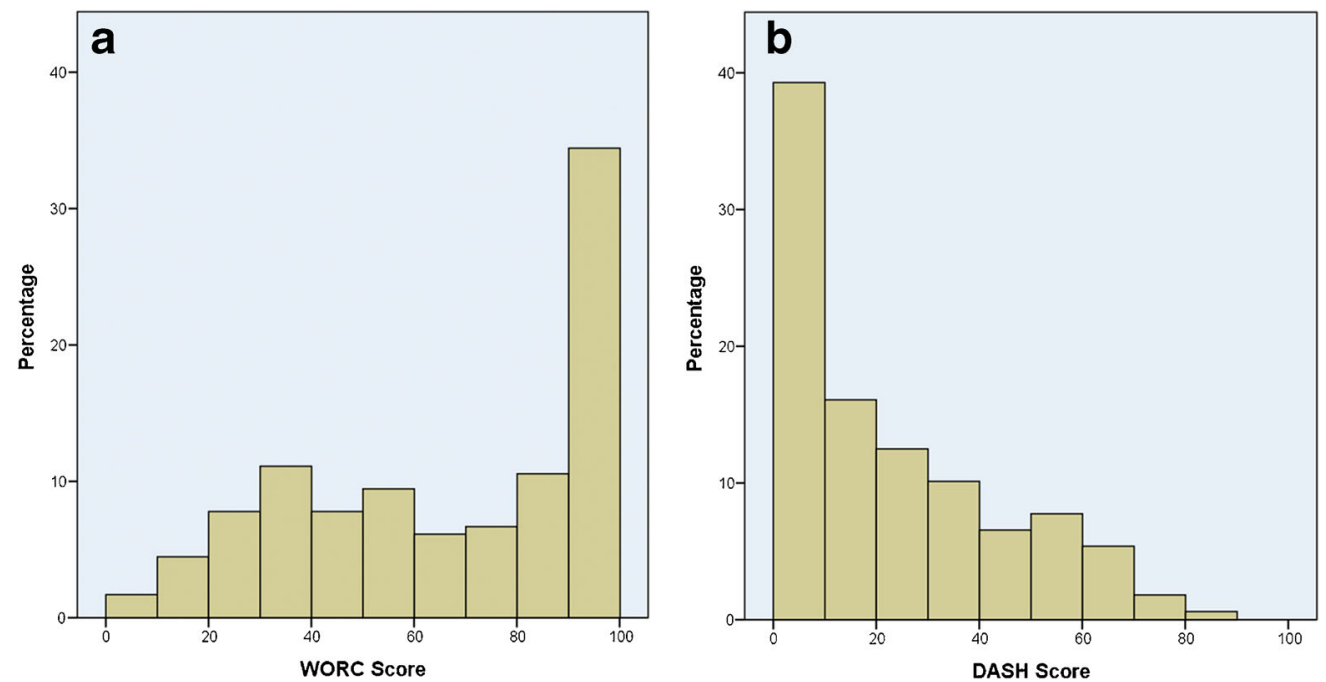

Fig. 4 Histograms of the clinical scores A) WORC score: $55 \%$ had inferior long-term functional outcome, with scores below 80 percentage points; $B$ ) DASH score: $45 \%$ scored had scores over 20 points, indicating disability 
Table 3 Univariate and multivariate analyses of the associations of baseline characteristics with inferior longterm clinical outcome, expressed in a WORC score $<80$ points

\begin{tabular}{|c|c|c|c|c|c|c|}
\hline \multirow[t]{2}{*}{ WORC $<80$} & \multicolumn{3}{|c|}{ Univariate } & \multicolumn{3}{|c|}{ Multivariate } \\
\hline & OR & $95 \% \mathrm{CI}$ & $p$ & OR & $95 \% \mathrm{CI}$ & $p$ \\
\hline Female gender & 1.82 & $0.99-3.35$ & 0.05 & 2.16 & $1.11-420$ & 0.02 \\
\hline Age diagnosis & 1.00 & $0.97-1.04$ & 0.83 & & & \\
\hline Age questionnaire & 1.02 & $0.98-1.05$ & 0.36 & 1.00 & $0.96-1.04$ & 0.85 \\
\hline Years after diagnosis & 1.02 & $0.98-1.06$ & 0.35 & 0.99 & $0.94-1.04$ & 0.68 \\
\hline Diabetic & 3.01 & $0.61-14.89$ & 0.18 & & & \\
\hline Duration of symptoms (per additional month) & 1.02 & $1.00-1.03$ & 0.01 & & & \\
\hline Bilateral disease & 2.63 & $1.24-5.57$ & 0.01 & 2.18 & $0.94-5.10$ & 0.07 \\
\hline Dominant side affected & 2.00 & $1.01-3.96$ & 0.05 & 1.69 & $0.79-3.60$ & 0.18 \\
\hline \multicolumn{7}{|l|}{ Affected tendon(s) } \\
\hline Supraspinatus & 0.73 & $0.23-2.31$ & 0.59 & & & \\
\hline Infraspinatus & 1.07 & $0.43-2.64$ & 0.89 & & & \\
\hline Subscapularis & 1.17 & $0.32-4.26$ & 0.82 & & & \\
\hline \multicolumn{7}{|l|}{ Treatment } \\
\hline Barbotage & 1.00 & $0.54-1.86$ & 0.99 & 1.13 & $0.56-2.28$ & 0.74 \\
\hline Calcification location (mm) & 0.98 & $0.92-1.06$ & 0.63 & & & \\
\hline Calcification size (mm) & 0.98 & $0.91-1.06$ & 0.64 & & & \\
\hline Gärtner calcification classification & & & 0.87 & & & \\
\hline 1 & Ref. & & & & & \\
\hline 2 & 0.93 & $0.36-2.39$ & 0.89 & & & \\
\hline 3 & 1.19 & $0.42-3.36$ & 0.75 & & & \\
\hline Number of calcifications (per additional deposit) & 2.12 & $0.97-4.62$ & 0.06 & & & \\
\hline
\end{tabular}

Radiological data were available in 204 patients for Gärtner classification, affected tendon, and number of calcifications (analogue and digital radiographs), and in 50 patients for Size and Location (digital radiographs, calibrated). These data were not included in the multivariate analysis

95 \%-CI: 95 \%-Confidence Interval contrast to our results, with average Constant Scores $>90$ points at 10 years [9]. In accordance with our results, they found no difference in clinical outcome between barbotage and conservative treatment. However, their conservative group consisted of patients refusing to undergo barbotage, who instead underwent unreported other treatment methods and had a high drop-out rate. A possible explanation for their superior results is that the mean age at diagnosis was 40.2 years, compared to our 49.0 years. Also, RCCT was diagnosed in 323 shoulders in \pm 3 years, versus 420 patients in 29 years at our institution. The latter might be partially due to both the high density of hospitals and the fact that a general practitioner functions as a gatekeeper for the referral to a medical specialist in our country. Both can potentially limit the referral of patients for treatment, specifically in cases with mild symptoms. Finally, it is possible that referring physicians are more familiar with RCCT and its treatment in the geographical region of Serafini. This could lead to earlier diagnosis, at a younger age, and earlier referral and adequate treatment. Concordantly, our univariate analyses show that longer duration of symptoms at presentation is related to inferior long-term outcome. Lastly, the Constant Score as applied by Serafini et al. is a general shoulder function score, in contrast to the WORC, which is a validated score for rotator cuff problems specifically.

\section{Demographics and prognostic characteristics}

Dominant arm involvement was associated with inferior longterm outcome. A plausible explanation is that dominant arm involvement has a larger influence on the patient's life. The dominant arm was also more often affected than the nondominant arm. This is in contrast to most studies that either find no influence of arm dominance on outcome, or did not analyze this effect $[9,67,68]$. Bilateral disease had a negative association with clinical outcome, which is supported by others $[3,16]$.

The higher incidence of RCCT in women is in accordance with most other studies. Some explain this by the higher prevalence of endocrine disorders in women (thyroid and estrogen metabolism) [67]. Of all recorded thyroid disorders we identified from the medical records, the majority $(75 \%)$ was in females. Similarly, of all patients with concomitant tendon disorders, $66.6 \%$ were female. Although these data are probably underreported and we did not investigate underlying 
Table 4 Univariate and multivariate analyses of the associations of baseline characteristics with inferior longterm clinical outcome, expressed in a DASH $>20$ points

\begin{tabular}{|c|c|c|c|c|c|c|}
\hline \multirow[t]{2}{*}{ Dash $>20$} & \multicolumn{3}{|c|}{ Univariate } & \multicolumn{3}{|c|}{ Multivariate } \\
\hline & OR & $95 \% \mathrm{CI}$ & $\mathrm{p}$ & OR & $95 \% \mathrm{CI}$ & $\mathrm{p}$ \\
\hline Female gender & 1.58 & $0.85-2.97$ & 0.15 & 2.03 & $1.02-4.02$ & 0.04 \\
\hline Age diagnosis & 1.01 & $0.98-1.05$ & 0.49 & & & \\
\hline Age questionnaire & 1.01 & $0.98-1.05$ & 0.57 & 1.01 & $0.97-1.05$ & 0.64 \\
\hline Years after diagnosis & 1.00 & $0.96-1.04$ & 0.98 & 1.01 & $0.95-1.07$ & 0.79 \\
\hline Diabetic & 2.61 & $0.63-10.8$ & 0.19 & & & \\
\hline Duration of symptoms (per additional month) & 1.01 & $0.99-1.02$ & 0.13 & & & \\
\hline Bilateral disease & 1.61 & $0.79-3.25$ & 0.19 & 1.49 & $0.62-3.13$ & 0.42 \\
\hline Dominant side affected & 2.07 & $0.99-4.33$ & 0.05 & 1.92 & $0.85-4.32$ & 0.12 \\
\hline \multicolumn{7}{|l|}{ Affected tendon(s) } \\
\hline Supraspinatus & 0.44 & $0.15-1.30$ & 0.14 & & & \\
\hline Infraspinatus & 1.11 & $0.46-2.72$ & 0.81 & & & \\
\hline Subscapularis & 1.88 & $0.57-6.21$ & 0.30 & & & \\
\hline \multicolumn{7}{|l|}{ Treatment } \\
\hline Barbotage & 0.76 & $0.41-1.44$ & 0.40 & 0.64 & $0.31-1.31$ & 0.22 \\
\hline Calcification location (mm) & 1.02 & $0.95-1.09$ & 0.61 & & & \\
\hline Calcification size (mm) & 0.98 & $0.91-1.06$ & 0.64 & & & \\
\hline Gärtner calcification classification & & & 0.53 & & & \\
\hline 1 & Ref. & & & & & \\
\hline 2 & 1.08 & $0.40-2.95$ & 0.88 & & & \\
\hline 3 & 1.71 & $0.59-5.02$ & 0.33 & & & \\
\hline Number of calcifications (per additional deposit) & 1.19 & $0.62-2.28$ & 0.61 & & & \\
\hline
\end{tabular}

Radiological data were available in 204 patients for Gärtner classification, affected tendon, and number of calcifications (analogue and digital radiographs); and in 50 patients for Size and Location (digital radiographs, calibrated). These data were not included in the multivariate analysis

95 \%-CI: 95 \%-Confidence Interval associations, our results confirm a higher incidence of RCCT in the presence of systemic diseases in women.

We found no effect of treatment (barbotage vs. conservative) on long-term outcome. Because of the alleged selflimiting character of RCCT, treatment is usually conservative $[4,16,57]$. However, as supported by our results, symptoms can persist for more than a decade. Various more invasive methods have been reported for patients with severe or persisting symptoms, including ESWT [26, 28, 29], barbotage $[9,15,19,34,38]$, and surgery $[13,14]$. But reported outcomes are highly variable and only a few studies compare treatment methods. More research is needed to gain knowledge on indications and long-term effects of various treatment methods, specifically for the more invasive techniques.

\section{Radiological measures and prognostic characteristics}

This is one of the first studies assessing interobserver agreement and the prognostic value of radiological characteristics of calcifications: the Gärtner classification [6], calcification Size, and the Location measure of Ogon et al [3]. Both metric measures (Size, Location) had good ICCs and small mean interobserver differences. For the Gärtner classification, there was only moderate agreement (Kappa 0.47), comparable to previously reported values in a smaller patient group [48]. Our previous study showed, that the results of barbotage were particularly superior to subacromial injections in patients with Type II and III calcifications [6]. Therefore, we also assessed interobserver agreement for Type I vs. Type II/III calcifications, but there was a similar moderate agreement. Overall, we found no prognostic value of radiological characteristics. Confirmatory to this, others have reported that symptoms and treatment outcome do not depend on the calcific deposit classification and size at baseline, but patients with radiological improvement over time (e.g. decrease in size or Gärtner classification) do report better clinical results $[16,46]$. The latter was not investigated in our study. However, we did find a relevant association between a higher number of calcifications at baseline and inferior long-term outcome.

\section{Strengths and limitations}

There are some limitations that have to be taken into account when interpreting our results. Firstly, as with all retrospective 
studies, a substantial part of our data depends on accurate medical record keeping. Furthermore, selection bias could have played a role; 194 of 342 subjects could be included for the follow-up part of our study, and only a limited number also had radiographs available. However, the baseline characteristics of subjects who did not sent a reply were comparable to the evaluated subjects (Tables 1 and 2). Furthermore, sensitivity analyses including only subjects who had both radiographs and clinical scores available showed similar results (Supplementary Table S1). And despite the above, this is one of the largest studies with the longest follow-up of its kind.

Secondly, it is unclear whether the inferior long-term shoulder scores are due to persisting, residual, or recurrent RCCT, or other shoulder pathology (whether or not consequent to RCCT). Although it would be interesting to know whether subjects with inferior outcomes actually still have RCCT, the fact that many subjects (formerly) diagnosed with RCCT have serious symptoms in the long-term is very relevant information by itself: the clinical scores of many subjects in this study are inferior compared to the general population, even years after diagnosis. This is one of the first studies showing this phenomenon. Further research is needed to investigate underlying conditions in the long-term course of RCCT.

Thirdly, it is possible that some patients might have had (secondary) treatments in other institutions. However, our institution was one of few regional centers performing barbotage and other RCCT treatments during the study period. Furthermore, despite potential secondary treatments, we still found persisting symptoms in many subjects after more than a decade.

Lastly, there could have been confounding by indication. Patients who had barbotage are likely to have had other or more serious symptoms. Taking long-term outcome into account, OR's of treatment method were around 1.0 for WORC and DASH, meaning that if specifically patients with worse symptoms in the past had a barbotage, they had no inferior long-term outcome compared to the more conservatively treated patients.

\section{Conclusions}

In this observational study, we found that over $55 \%$ of RCCT patients, treated with either barbotage or more conservative modalities, have symptoms and impaired shoulder function at a mean of 14 years after diagnosis. These observations are in contrast to the general view that RCCT is a self-limiting disease. Dominant arm involvement, bilateral disease, a larger number of calcifications, female gender, and longer duration of symptoms were associated with inferior functional outcome. We found no associations between treatment method and baseline radiological characteristics with long-term outcome. Interobserver agreement of the radiological Gärtner classification was only moderate.
Applying these findings in clinical decision making might be helpful in preventing a long-term symptomatic course; it is plausible that a wait-and-see strategy or conservative treatments (not aimed at decreasing the calcium deposits) are not necessarily the most effective methods in patients with persisting symptoms, no signs of resorption over time, and one or more of the reported negative prognostic factors. We suggest taking into account these factors in future (prospective) studies, in order to evaluate whether earlierapplied and more invasive forms of treatment result in better outcome in selected patients.

Acknowledgments The authors would like to acknowledge Suzanne Cannegieter, MD, PhD (Epidemiology department, Leiden University Medical Center) for her help in the statistical analyses, Koos Mistrate Haarhuis and Jan Molenaar for their help in identifying patients with the relevant diagnostic codes, and Aart Westerlaken, Anneke Lapaer, and Ingrid Groenendijk (Radiology department, Leiden University Medical Center) for their help in retrieving the radiographs.

This study is part of a larger project funded by ZonMw, the Netherlands Organization for health research and development (NOW) (grant number 40-00703-98-8564), and the Dutch Arthritis Association (grant number 09-1-303).

The scientific guarantor of this publication is Prof. Dr. R.G.H.H. Nelissen. The authors of this manuscript declare no relationships with any companies whose products or services may be related to the subject matter of the article. Institutional Review Board approval was obtained. Written informed consent was obtained from all subjects (patients) in this study. Methodology: retrospective, observational, performed at one institution.

Open Access This article is distributed under the terms of the Creative Commons Attribution-NonCommercial 4.0 International License (http:// creativecommons.org/licenses/by-nc/4.0/), which permits any noncommercial use, distribution, and reproduction in any medium, provided you give appropriate credit to the original author(s) and the source, provide a link to the Creative Commons license, and indicate if changes were made.

\section{References}

1. Clavert P, Sirveaux F (2008) Shoulder calcifying tendinitis. Rev Chir Orthop Reparatrice Appar Mot 94:336-355

2. Diehl P, Gerdesmeyer L, Gollwitzer H, Sauer W, Tischer T (2011) Calcific tendinitis of the shoulder. Orthopade 40:733-746

3. Ogon P, Suedkamp NP, Jaeger M, Izadpanah K, Koestler W, Maier D (2009) Prognostic factors in nonoperative therapy for chronic symptomatic calcific tendinitis of the shoulder. Arthritis Rheum 60:2978-2984

4. Speed CA, Hazleman BL (1999) Calcific tendinitis of the shoulder. N Engl J Med 340:1582-1584

5. de Witte PB, Selten JW, Navas A et al (2013) Calcific tendinitis of the rotator cuff: a randomized controlled trial of ultrasound-guided needling and lavage versus subacromial corticosteroids. Am J Sports Med 41:1665-1673

6. Gartner J, Simons B (1990) Analysis of calcific deposits in calcifying tendinitis. Clin Orthop Relat Res (254):111-120 
7. Del Cura JL, Torre I, Zabala R, Legorburu A (2007) Sonographically guided percutaneous needle lavage in calcific tendinitis of the shoulder: short- and long-term results. AJR Am J Roentgenol 189:W128-W134

8. Rupp S, Seil R, Kohn D (2000) Tendinosis calcarea of the rotator cuff. Orthopade 29:852-867

9. Serafini G, Sconfienza LM, Lacelli F, Silvestri E, Aliprandi A, Sardanelli F (2009) Rotator cuff calcific tendonitis: short-term and 10 -year outcomes after two-needle us-guided percutaneous treatment-nonrandomized controlled trial. Radiology 252:157-164

10. Wang CJ, Yang KD, Wang FS, Chen HH, Wang JW (2003) Shock wave therapy for calcific tendinitis of the shoulder: a prospective clinical study with two-year follow-up. Am J Sports Med 31:425430

11. Wittenberg RH, Rubenthaler F, Wolk T, Ludwig J, Willburger RE, Steffen R (2001) Surgical or conservative treatment for chronic rotator cuff calcifying tendinitis-a matched-pair analysis of 100 patients. Arch Orthop Trauma Surg 121:56-59

12. Wolk T, Wittenberg RH (1997) Calcifying subacromial syndromeclinical and ultrasound outcome of non-surgical therapy. Z Orthop Ihre Grenzgeb 135:451-457

13. Ark JW, Flock TJ, Flatow EL, Bigliani LU (1992) Arthroscopic treatment of calcific tendinitis of the shoulder. Arthroscopy 8: 183-188

14. Balke M, Bielefeld R, Schmidt C, Dedy N, Liem D (2012) Calcifying tendinitis of the shoulder: midterm results after arthroscopic treatment. Am J Sports Med 40:657-661

15. Chiou HJ, Chou YH, Wu JJ et al (2001) The role of high-resolution ultrasonography in management of calcific tendonitis of the rotator cuff. Ultrasound Med Biol 27:735-743

16. Cho NS, Lee BG, Rhee YG (2010) Radiologic course of the calcific deposits in calcific tendinitis of the shoulder: does the initial radiologic aspect affect the final results? J Shoulder Elb Surg 19:267272

17. Comfort TH, Arafiles RP (1978) Barbotage of the shoulder with image-intensified fluoroscopic control of needle placement for calcific tendinitis. Clin Orthop Relat Res (135):171-178

18. Daecke W, Kusnierczak D, Loew M (2002) Extracorporeal shockwave therapy (ESWT) in tendinosis calcarea of the rotator cuff. Long-term results and efficacy. Orthopade 31:645-651

19. Farin PU, Jaroma H, Soimakallio S (1995) Rotator cuff calcifications: treatment with US-guided technique. Radiology 195:841843

20. Farin PU, Rasanen H, Jaroma H, Harju A (1996) Rotator cuff calcifications: treatment with ultrasound-guided percutaneous needle aspiration and lavage. Skelet Radiol 25:551-554

21. Farr S, Sevelda F, Mader P, Graf A, Petje G, Sabeti-Aschraf M (2011) Extracorporeal shockwave therapy in calcifying tendinitis of the shoulder. Knee Surg Sports Traumatol Arthrosc 19:20852089

22. Fusaro I, Orsini S, Diani S, Saffioti G, Zaccarelli L, Galletti S (2011) Functional results in calcific tendinitis of the shoulder treated with rehabilitation after ultrasonic-guided approach. Musculoskelet Surg 95:S31-S36

23. Gartner J, Heyer A (1995) Calcific tendinitis of the shoulder. Orthopade 24:284-302

24. Hurt G, Baker CL Jr (2003) Calcific tendinitis of the shoulder. Orthop Clin North Am 34:567-575

25. Jacobs R, Debeer P (2006) Calcifying tendinitis of the rotator cuff: functional outcome after arthroscopic treatment. Acta Orthop Belg 72:276-281

26. Lee SY, Cheng B, Grimmer-Somers K (2011) The midterm effectiveness of extracorporeal shockwave therapy in the management of chronic calcific shoulder tendinitis. J Shoulder Elb Surg 20:845854
27. Moretti B, Garofalo R, Genco S, Patella V, Mouhsine E (2005) Medium-energy shock wave therapy in the treatment of rotator cuff calcifying tendinitis. Knee Surg Sports Traumatol Arthrosc 13:405410

28. Mouzopoulos G, Stamatakos M, Mouzopoulos D, Tzurbakis M (2007) Extracorporeal shock wave treatment for shoulder calcific tendonitis: a systematic review. Skelet Radiol 36:803-811

29. Noel E, Charrin J (1999) Extracorporeal shock wave therapy in calcific tendinitis of the shoulder. Rev Rhum Engl Ed 66:691-693

30. Peters J, Luboldt W, Schwarz W, Jacobi V, Herzog C, Vogl TJ (2004) Extracorporeal shock wave therapy in calcific tendinitis of the shoulder. Skelet Radiol 33:712-718

31. Pfister J, Gerber H (1997) Chronic calcifying tendinitis of the shoulder-therapy by percutaneous needle aspiration and lavage: a prospective open study of 62 shoulders. Clin Rheumatol 16:269 274

32. Pigozzi F, Giombini A, Parisi A et al (2000) The application of shock-waves therapy in the treatment of resistant chronic painful shoulder. A clinical experience. J Sports Med Phys Fitness 40:356 361

33. Rotini R, Bungaro P, Antonioli D, Katusic D, Marinelli A (2005) Algorithm for the treatment of calcific tendinitis in the rotator cuff: indications for arthroscopy and results in our experience. Chir Organi Mov 90:105-112

34. Sconfienza LM, Serafini G, Sardanelli F (2011) Treatment of calcific tendinitis of the rotator cuff by ultrasound-guided single-needle lavage technique. AJR Am J Roentgenol 197:W366

35. Seil R, Litzenburger H, Kohn D, Rupp S (2006) Arthroscopic treatment of chronically painful calcifying tendinitis of the supraspinatus tendon. Arthroscopy 22:521-527

36. Wainner RS, Hasz M (1998) Management of acute calcific tendinitis of the shoulder. J Orthop Sports Phys Ther 27:231-237

37. Yoo JC, Koh KH, Park WH, Park JC, Kim SM, Yoon YC (2010) The outcome of ultrasound-guided needle decompression and steroid injection in calcific tendinitis. J Shoulder Elb Surg 19:596-600

38. Lanza E, Banfi G, Serafini G et al (2015) Ultrasound-guided percutaneous irrigation in rotator cuff calcific tendinopathy: what is the evidence? A systematic review with proposals for future reporting. Eur Radiol 25:2176-2183

39. Uhthoff HK (1975) Calcifying tendinitis, an active cell-mediated calcification. Virchows Arch A Pathol Anat Histol 366:51-58

40. Uhthoff HK, Sarkar K, Maynard JA (1976) Calcifying tendinitis: a new concept of its pathogenesis. Clin Orthop Relat Res (118):164168

41. Gartner J (1993) Is tendinosis calcarea associated with HLA-A1. Z Orthop Ihre Grenzgeb 131:469

42. Hamada J, Ono W, Tamai K, Saotome K, Hoshino T (2001) Analysis of calcium deposits in calcific periarthritis. J Rheumatol 28:809-813

43. Schulz CU, Maier M, Glaser C, Anetzberger H, Muller-Gerbl M (2006) Pathologic glenohumeral stress distribution in calcific tendinosis of the supraspinatus. Z Orthop Ihre Grenzgeb 144:311315

44. Siegal DS, Wu JS, Newman JS, Del Cura JL, Hochman MG (2009) Calcific tendinitis: a pictorial review. Can Assoc Radiol J 60:263272

45. Uhthoff HK (1996) Calcifying tendinitis. Ann Chir Gynaecol 85: $111-115$

46. Krasny C, Enenkel M, Aigner N, Wlk M, Landsiedl F (2005) Ultrasound-guided needling combined with shock-wave therapy for the treatment of calcifying tendonitis of the shoulder. J Bone Joint Surg (Br) 87:501-507

47. Maier M, Schmidt-Ramsin J, Glaser C, Kunz A, Kuchenhoff H, Tischer T (2008) Intra- and interobserver reliability of classification scores in calcific tendinitis using plain radiographs and CT scans. Acta Orthop Belg 74:590-595 
48. Maier M, Maier-Bosse T, Eckermann M et al (2003) The roentgenmorphologic aspects of symptomatic calcifications in patients with calcifying tendinitis of the shoulder: determination of intra- and interobserver variabilities of Gartner's classification. Unfallchirurg 106:185-189

49. Pasquotti G, Faccinetto A, Marchioro U et al (2015) US-guided percutaneous treatment and physical therapy in rotator cuff calcific tendinopathy of the shoulder: outcome at 3 and 12 months. Eur Radiol. doi:10.1007/s00330-015-4102-8

50. Kirkley A, Griffin S, Dainty K (2003) Scoring systems for the functional assessment of the shoulder. Arthroscopy 19:1109-1120

51. Hudak PL, Amadio PC, Bombardier C (1996) Development of an upper extremity outcome measure: the DASH (disabilities of the arm, shoulder and hand) [corrected]. The Upper Extremity Collaborative Group (UECG). Am J Ind Med 29:602-608

52. de Witte PB, Henseler JF, Nagels J, Vliet Vlieland TP, Nelissen RG (2012) The Western ontario rotator cuff index in rotator cuff disease patients: a comprehensive reliability and responsiveness validation study. Am J Sports Med 40:1611-1619

53. Daecke W, Kusnierczak D, Loew M (2002) Long-term effects of extracorporeal shockwave therapy in chronic calcific tendinitis of the shoulder. J Shoulder Elb Surg 11:476-480

54. Balke M, Bielefeld R, Schmidt C, Dedy N, Liem D (2012) Calcifying Tendinitis of the Shoulder: Midterm Results After Arthroscopic Treatment. Am J Sports Med 40:657-661

55. Galletti S, Magnani M, Rotini R et al (2004) The echo-guided treatment of calcific tendinitis of the shoulder. Chir Organi Mov 89:319-323

56. Hofstee DJ, Gosens T, Bonnet M, De Waal MJ (2007) Calcifications in the cuff: take it or leave it? Br J Sports Med 41: 832-835

57. Litchman HM, Silver CM, Simon SD, Eshragi A (1968) The surgical management of calcific tendinitis of the shoulder. An analysis of 100 consecutive cases. Int Surg 50:474-479

58. Marder RA, Heiden EA, Kim S (2011) Calcific tendonitis of the shoulder: is subacromial decompression in combination with removal of the calcific deposit beneficial? J Shoulder Elb Surg 20:955-960

59. Rompe JD, Zoellner J, Nafe B (2001) Shock wave therapy versus conventional surgery in the treatment of calcifying tendinitis of the shoulder. Clin Orthop Relat Res:72-82

60. Vebostad A (1975) Calcific tendinitis in the shoulder region. Acta Orthop Scand 46:205-210

61. Yoo JC, Park WH, Koh KH, Kim SM (2010) Arthroscopic treatment of chronic calcific tendinitis with complete removal and rotator cuff tendon repair. Knee Surg Sports Traumatol Arthrosc 18: 1694-1699

62. Adamietz B, Schulz-Wendtland R, Alibek S et al (2010) Calcifying tendonitis of the shoulder joint : predictive value of pretreatment sonography for the response to low-dose radiotherapy. Strahlenther Onkol 186:18-23

63. Cosentino R, Selvi E, De SR et al (2004) Extracorporeal shock wave therapy for chronic calcific tendinitis of the shoulder. Clin Rheumatol 23:475-477

64. Gerdesmeyer L, Wagenpfeil S, Haake M et al (2003) Extracorporeal shock wave therapy for the treatment of chronic calcifying tendonitis of the rotator cuff: a randomized controlled trial. JAMA 290:2573-2580

65. Loew M, Daecke W, Kusnierczak D, Rahmanzadeh M, Ewerbeck V (1999) Shock-wave therapy is effective for chronic calcifying tendinitis of the shoulder. J Bone Joint Surg (Br) 81:863-867

66. Rompe JD, Burger R, Hopf C, Eysel P (1998) Shoulder function after extracorporal shock wave therapy for calcific tendinitis. J Shoulder Elb Surg 7:505-509

67. Harvie P, Pollard TC, Carr AJ (2007) Calcific tendinitis: natural history and association with endocrine disorders. J Shoulder Elb Surg 16:169-173

68. Kircher J, Morhard M, Patzer T, Magosch P, Lichtenberg S, Habermeyer P (2012) Do anatomic variants of the acromion shape in the frontal plane influence pain and function in calcifying tendinitis of the shoulder? Knee Surg Sports Traumatol Arthrosc 20: $368-372$ 